\title{
Electrochemical migration technique to accelerate ageing of cementitious materials
}

\author{
A. Babaahmadi ${ }^{1, \mathrm{a}}$, L. Tang ${ }^{2}$, and Z. Abbas ${ }^{3}$ \\ ${ }^{1} \mathrm{PhD}$ candidate, Chalmers University, SE-41296 Gothenburg, Sweden \\ ${ }^{2}$ Professor, Chalmers University, SE-41296 Gothenburg, Sweden \\ ${ }^{3}$ Associate Professor, Chalmers University, SE-41296 Gothenburg, Sweden
}

\begin{abstract}
Durability assessment of concrete structures for constructions in nuclear waste repositories requires long term service life predictions. As deposition of low and intermediate level radioactive waste (LILW) takes up to 100000 years, it is necessary to analyze the service life of cementitious materials in this time perspective. Using acceleration methods producing aged specimens would decrease the need of extrapolating short term data sets. Laboratory methods are therefore, needed for accelerating the ageing process without making any influencing distortion in the properties of the materials. This paper presents an electro-chemical migration method to increase the rate of calcium leaching from cementitious specimens. This method is developed based on the fact that major long term deterioration process of hardened cement paste in concrete structures for deposition of LILW is due to slow diffusion of calcium ions. In this method the cementitious specimen is placed in an electrochemical cell as a porous path way through which ions can migrate at a rate far higher than diffusion process. The electrical field is applied to the cell in a way to accelerate the ion migration without making destructions in the specimen's micro and macroscopic properties. The anolyte and catholyte solutions are designed favoring dissolution of calcium hydroxide and compensating for the leached calcium ions with another ion like lithium.
\end{abstract}

\section{Introduction}

Concrete as an economic construction material with good $\mathrm{pH}$ buffering capacity is used extensively within the construction of nuclear waste repositories. As of dealing with low and intermediate level radioactive waste (LILW), the risk assessments require service life of up to 100000 years. In this time perspective using predictions from short term experimental data sets would introduce a big risk of extrapolation within the results. Considering the fact that in this time period the major deterioration factor is the contact between ground water and the structure, the long term degradation can be simulated using experimental methods. The water, having low calcium content will cause dissolution of the main hydration products of cementitious material, which are calcium hydroxide and calcium silicate hydrates and as a result leaching of calcium would be dominant. There are many

\footnotetext{
a e-mail: arezou.babaahmadi@chalmers.se
}

This is an Open Access article distributed under the terms of the Creative Commons Attribution License 2.0, which permits unrestricted use, distribution, and reproduction in any medium, provided the original work is properly cited. 
studies reported in the literature regarding leaching of calcium from cementitious materials based on immersion of the cementitious specimens in water [1-3]. The results indicate that a layered system is developed in the leached samples comprising a core characterized by total dissolution of Portlandite followed by different zones separated by dissolution/precipitation fronts and progressive decalcification of the C-S-H gel [1]. However although some conclusions can be drawn from these studies regarding the properties of aged cementitious materials, these experiments are very time consuming due to the slow kinetics of the decalcification process. Consequently in order to facilitate the experiments as well as minimizing the uncertainties introduced when extrapolating short-term experimental data, some acceleration methods have been developed. These acceleration methods are either based on chemical or electrical processes. The electrical methods are based on the migration concept which enhances transport of the charged substances with an electrical field [4-7], whilst chemical methods are based on the application of chemicals which enhance the rate of calcium dissolution from calcium containing phases [8-10].

A primary electrical acceleration method was reported by Saito et al. [5]. In this method a disc of mortar sample was placed between two glass vessels containing water as electrolyte. Carbon electrodes were used both as cathode and anode and a constant potential was applied during the experiment. Although the results showed effective acceleration in treated specimens with strong decrease of $\mathrm{Ca} / \mathrm{Si}$ ratio but the $\mathrm{pH}$ changes in electrolyte solution was not reported. This inspires scenarios of the possible acidic characteristics of the anolyte solution due to production $\mathrm{of}^{+}$ions around anode, which may interfere with simulating the natural leaching process.

Among the chemical methods presented in the literature the application of concentrated ammonium nitrate instead of immersion of cementitious materials in deionized water has been frequently studied $[8,9,11]$. In this method paste specimens were immersed in $6 \mathrm{M}$ ammonium nitrate. Although the acceleration rate is very high, the small size of the aged samples limits further physical tests such as diffusivity or permeability. Moreover, since the method should represent the natural leaching process during the leaching of portlandite content there should not be any interaction with CSH phases, however the effect of the method on microstructure is not studied in detail.

It should be noted that acceleration might promote mechanisms not necessarily corresponding to natural leaching process. For example application of an electrical field will accelerate movement of both negative and positive ions in different directions which makes the ageing process different from natural leaching not only concerning rates but also the direction of the flow and selectivity. However trough experimental simulation of the leaching process and combining the experimental databases with corresponding modeling a frame work can be established to extrapolate the attained results to long term conditions.

In this paper an electrochemical migration method is presented. The goal is to accelerate the leaching of Portlandite content in cementitious specimens with a size suitable for further physical and mechanical tests and without significant interaction with $\mathrm{CSH}$ phases. The chemical and mineralogical properties of the aged specimens are studied and the capability of the new method in producing comparable aged specimens as in natural immersion condition is demonstrated.

\subsection{Test specimens}

In order to facilitate the mineralogical analysis paste specimens were used in this study. With watercement ratio of 0.5 , Swedish structural Portland cement, Table1, was mixed with distilled water and casted in acrylic cylinders with internal diameter of $50 \mathrm{~mm}$ and length of $250 \mathrm{~mm}$. using rubber stops the ends of the cylinders were sealed and in order to homogenize the paste the cylinders were rotated longitudinally with a rate of $12-14 \mathrm{rpm}$ during the first 24 hours of hydration. The specimens were stored for six month in a moist plastic box with saturated lime water in the bottom in order to prevent carbonation. 
Table 1. Chemical characteristics of Swedish CEM I 42.5N BV/SR/LA

\begin{tabular}{|l|l|l|l|l|l|l|l|l|l|}
\hline Chemical formulation & $\mathrm{CaO}$ & $\mathrm{SiO}_{2}$ & $\mathrm{Al}_{2} \mathrm{O}_{3}$ & $\mathrm{Fe}_{2} \mathrm{O}_{3}$ & $\mathrm{MgO}$ & $\mathrm{Na}_{2} \mathrm{O}$ & $\mathrm{K}_{2} \mathrm{O}$ & $\mathrm{SO}_{3}$ & $\mathrm{Cl}$ \\
\hline Percentage & 64 & 22.2 & 3.6 & 4.4 & 0.94 & 0.07 & 0.72 & 2.2 & 0.01 \\
\hline
\end{tabular}

\subsection{Experimental method}

The experimental setup in this study enables application of both electrical and chemical acceleration. The idea of using electrical acceleration to develop the rapid chloride migration test by Tang [12] as well as the chemical acceleration method with the application of concentrated ammonium nitrate to change the dissolution rates of calcium phases presented by Cared and Heukamp $[8,9]$ are the main inspirations for the setup design of this method. The setup is presented in Figure 1, pointing out the application of a specimen with the size of $\varnothing 50 \times 75 \mathrm{~mm}$ placed in an electro chemical cell. Up to half of the specimen's surface area is sealed using an asphalt tape and the sealant is up to 3 times longer than that of the specimen's providing an empty volume of about $300 \mathrm{ml}$ which is used as the anolyte container. It should be noted that in order to homogenize the effect of electrical gradient the specimen is turned half way of experimental time. The anode is made of titanium mesh and is placed in the anolyte container. It is equipped with a plastic support preventing direct contact with the specimen's top surface. The catholyte container is a plastic box with a capacity of about 20 liters. The cathode is made of stainless steel and is mounted on a plastic support placed in the catholyte container. The anode and cathode are connected to an external potential supplier with an adjustable current and voltage meters. In order to register the voltage and current values during the experimental time the external potential supplier is connected to a data log system. The external energy supplier is adjusted to $250 \mathrm{~mA}$ constant current during the experiment and the changes of potential values are registered using the data log system. It should be noted that the setup parameters are gradually refined based on several experimental trials in order to facilitate the leaching while reducing the negative effects through acceleration.

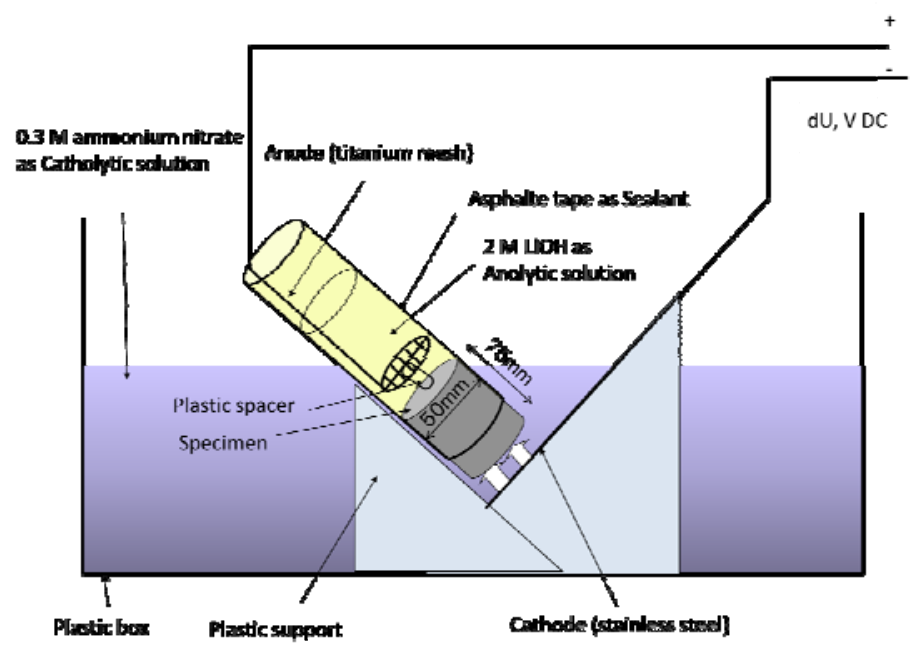

Figure 1. Experimental setup

The catholyte is $0.3 \mathrm{M}$ ammonium nitrate solution. Migration of nitrate ions to the specimen favors dissolution of calcium hydroxides considering the higher dissolution rate of calcium nitrates 
(Equation 1). The ammonium is in equilibrium with ammonia and $\mathrm{H}^{+}$ions. The $\mathrm{H}^{+}$ions consume the $\mathrm{OH}^{-}$ions produced at the cathode. However the $\mathrm{pH}$ of the solution should be monitored and the catholyte solution should be refreshed frequently. High alkalinity in catholyte ensue migration of hydroxide ions to the specimen leading to lower rate in decalcification process.

The anolyte solution is $2 \mathrm{M}$ lithium hydroxide solution providing a non-corrosive alkaline environment around the anode as well as enabling migration of calcium ions from the specimen's pore solution replaced by lithium ions with low diffusive characteristics due to their effective ionic radius [13]. The ionic migration of ions in the system is presented in Figure 3.

$$
\begin{aligned}
& \mathrm{Ca}(\mathrm{OH})_{2}+2 \mathrm{NH}_{4} \mathrm{NO}_{3} \longleftrightarrow \mathrm{Ca}^{+2}+2 \mathrm{OH}^{-}+2 \mathrm{NH}_{3}+2 \mathrm{NO}_{3}^{-} \\
& \longleftrightarrow \mathrm{Ca}\left(\mathrm{NO}_{3}\right)_{2}+2 \mathrm{NH}_{3 \mathrm{~g}}+2 \mathrm{H}_{2} \mathrm{O}
\end{aligned}
$$

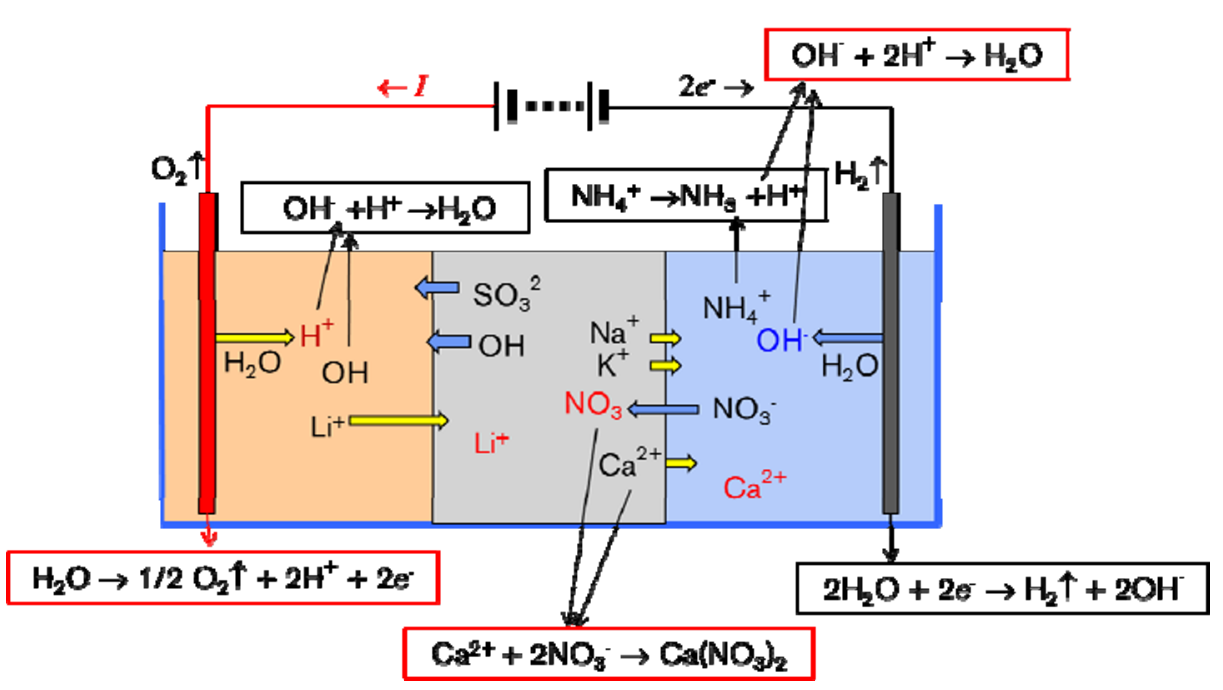

Figure 2. migartions of ions from and in to the specimen

In order to maintain the $\mathrm{pH}$ level in the catholyte and anolyte solutions as well as to compensate for the consumed ions $\left(\mathrm{NO}_{3}\right.$ ions in the anolyte solution and $\mathrm{H}^{+}$ions in the catholyte solution), the solutions were frequently recharged. The quantities of the salts required for recharging were calculated according to the Faraday's rule of electrolysis as given in Equation (2).

$$
I \cdot t=F \cdot z \cdot\left(\frac{m}{M}\right)
$$

where,
I: Current (A)
$t$ : time (seconds)
$F$ : Faraday number $=96485(\mathrm{C} / \mathrm{mol})$ 
M: Molecular weight of substance $(\mathrm{g} / \mathrm{mol})$

$m$ : mass of substance $(\mathrm{g})$

$z$ : the valance number of ions

With the application of a current of $0.25 \mathrm{~A}, 18$ grams of ammonium nitrate and 10 grams of lithium hydroxide per specimen were needed (in powder form) to recharge the catholyte and anolyte solutions, respectively, for every 24 hours of the experimental time.

\section{Chemical and mineralogical analysis}

The catholyte solution was frequently sampled during the experiments and the calcium content in catholyte solution was analyzed by potentiometric titration on a Metrohm Titrator 702 SM Titrino, using a calcium selective electrode and $0.1 \mathrm{~N}$ EDTA-solution as titrant. The amount of leached calcium during the experimental time is presented in Figure 3. Considering $\mathrm{C}_{3} \mathrm{~S}_{2} \mathrm{H}_{3}$ being the composition of $\mathrm{CSH}$ content and $\mathrm{CH}$ that of the portlandite, the calculation of the calcium and silica content of the specimen is presented in Table 2. Comparing figure 4 with Table 2, it can be seen that the amount of leached calcium is more than 99 percent of the total Portlandite content in the treated specimen.

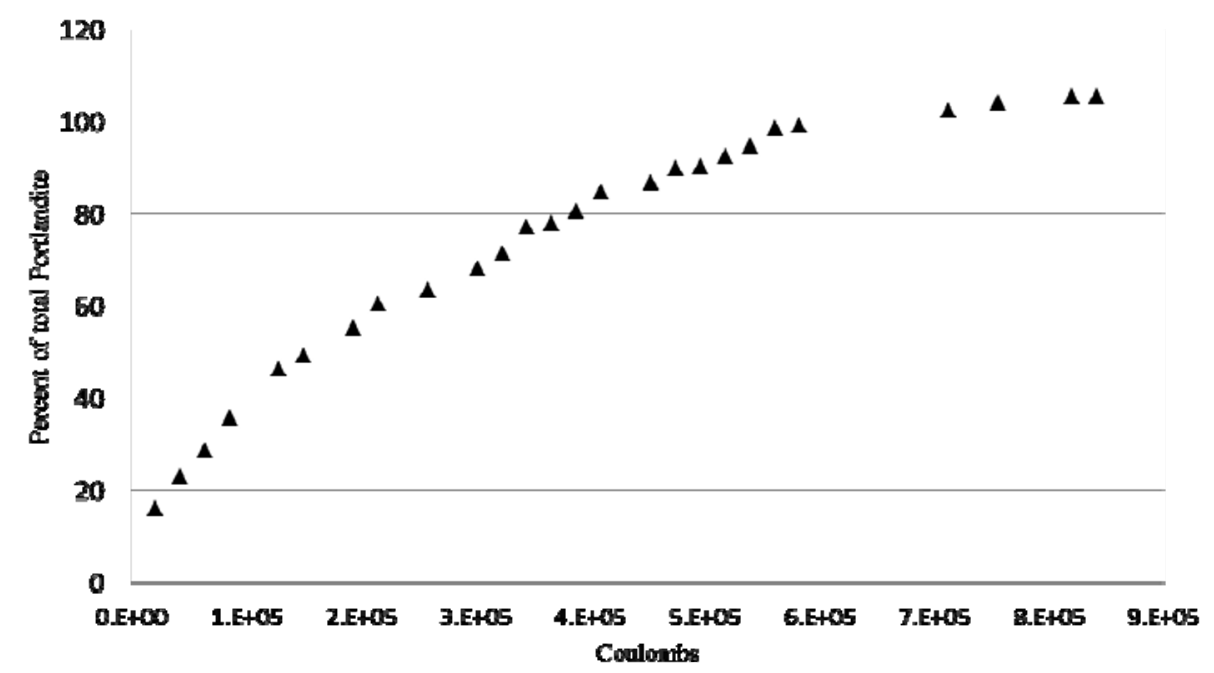

Figure 3. Leached calcium content (Moles)

Table 2. Calculation of initial Calcium and Silica content

\begin{tabular}{|l|l|l|l|}
\hline Total & Componenet & mole/gr cement & mole/specimen (229 gr cement/specimen) \\
\hline \multirow{3}{*}{ Calcium content } & CSH & $0.00145 * 3=0.00435$ & $0.332 * 3=0.996$ \\
\cline { 2 - 4 } & CH & 0.00303 & 0.693 \\
\cline { 2 - 4 } & Total & 0.00738 & 1.689 \\
\hline Silica content & CSH & $0.00145 * 2=0.0029$ & $0.332 * 2=0.664$ \\
\hline
\end{tabular}


Figure 4, presents the chronicle visual changes in the cross-sectional area of an altered specimen. It should be noted that the pictures are taken 10 minutes after wet cutting. It can be seen that the untreated specimen dries faster. Moreover, the altered specimen can be seen as a layered structure. It should be noted that according to natural immersion tests, the altered material through natural leaching process can be seen as a layered system [1].

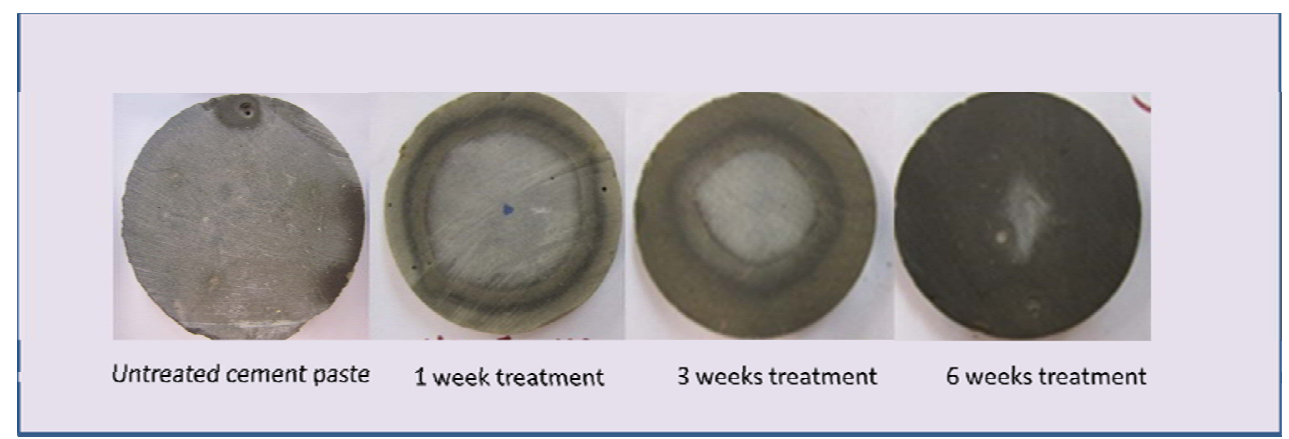

Figure 4. Chronicle visual changes in the cross-sectional area of an altered specimen

In order to account for the mineralogical properties of different layers observed in the cross section of the treated specimens, X-Ray analysis was carried out.

The characterization of the crystalline phases in the solid samples was performed with X-Ray Diffraction (XRD) analysis. A Siemens D5000 (CuK $\alpha=1.5418 \AA)$ X-Ray Diffractometer, equipped with Gobel mirror was used. The measurements were carried out by using $0.050^{\circ}$ per step and at a time step of $2 \mathrm{~s}$. The powder sample was prepared by crushing and grinding the solid sample in a mortel while immersed in ethanol and vacuum drying after grinding. For each analysis 0.5 grams of the powder was placed on a thin-walled glass sample holder to perform the assessment.

The changes in $\mathrm{Ca} / \mathrm{Si}$ ratio was obtained from the individual concentrations of calcium and silicon measured by means of X-Ray Fluorescence (XFR) spectroscopy. The solid samples were analyzed in a powder form and the powders were prepared with the same method as for XRD analysis. For each analysis 0.1 grams of powder sample was used. A three axial geometry spectrometer, built of Wanode X-Ray tube and Mo secondary target with a $\mathrm{Si}(\mathrm{Li})$ detector of $80 \mathrm{~mm}^{2}$ active area and a resolution of $175 \mathrm{eV}$ FWHM for Mn-K $\alpha$ X-Rays, as described by Boman [14] was used. The spectrum acquisition time was $1000 \mathrm{~s}$ at a tube voltage of $55 \mathrm{KV}$ and a current of $15 \mathrm{~mA}$. In this study the results from the XRF analysis are presented as a function of the changes of calcium to

silica ratio of the treated specimens compared to the original ratio, i.e. ${ }_{\text {Si }}$ Treated $_{\text {Re ference }}$. Figure

5 illustrates the sample numbering. It is shown that the outer brownish layer is numbered 1 , the thin black circle is 2 and the greyish area in the middle is numbered 3.

The XRD results indicate that the samples with the same number are showing the same crystalline structure. Moreover as presented in Figure 6, the outer brownish layer (1) as well as the blackish thin circle zone (2) are not containing Portlandite. However, the grayish middle section (3) contains Portlandite although the peaks are slightly lowered.

The XRF results are presented in Figure 7, the greyish middle part of the sample shows the same $\mathrm{Ca} / \mathrm{Si}$ ratio as the reference. However, in the outer brownish layer and the middle black circle zone the $\mathrm{Ca} / \mathrm{Si}$ ratio is decreased. It should be noted that according to $\mathrm{Ca} / \mathrm{Si}$ ratio the leached calcium content is almost equal to Portlandite content in the specimens (according to table $\mathrm{x}$ ).

Both XRD and XRF analysis are not showing considerable changes in CSH peaks or the concentration of $\mathrm{Si}$ in the samples indicating that the acceleration method does not cause significant interactions with $\mathrm{CSH}$ phases. 


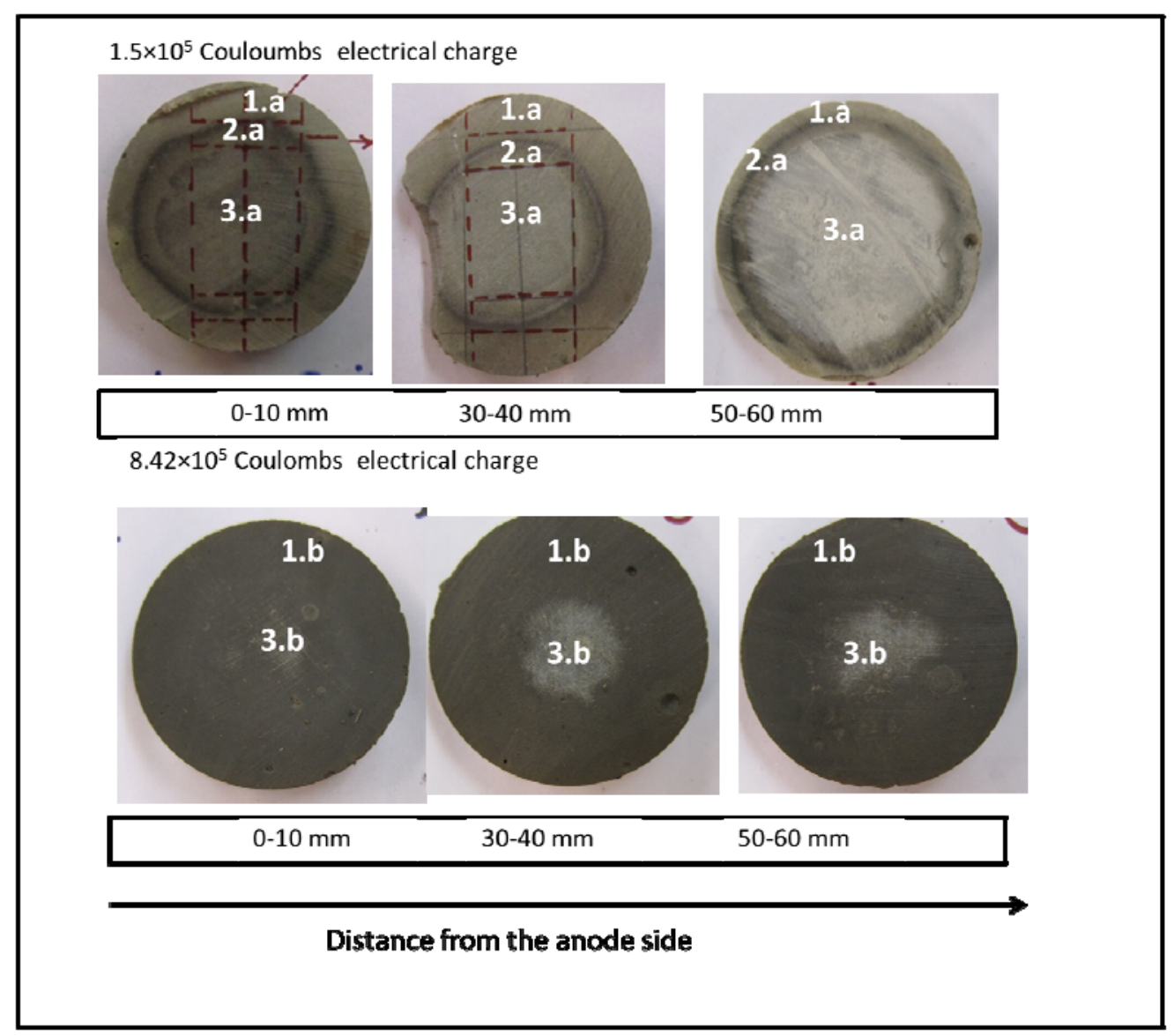

Figure 5. Sample numbering for X-Ray analysis

The surface topography of the solid samples was analyzed with Scanning Electron Microscopy (SEM) analysis. A FEI Quanta ESEM 200 equipped with field emission gun and Oxford Inca EDX system was used to perform the analysis. Thin cubes of the solid sample of about $20 \times 10 \mathrm{~mm}$, thickness of $10 \mathrm{~mm}$ were used. The samples were vacuum dried prior to analysis. It should be noted that the samples were neither polished nor coated which may cause charging effects in the results as well as uncertainties due to uneven surface of the sample. The analysis were performed in high vacuum mode and in 10-12 working distance from the detector. The results, indicate that the leached specimens are found to be very porous compared to the untreated specimens, Figure 8. 


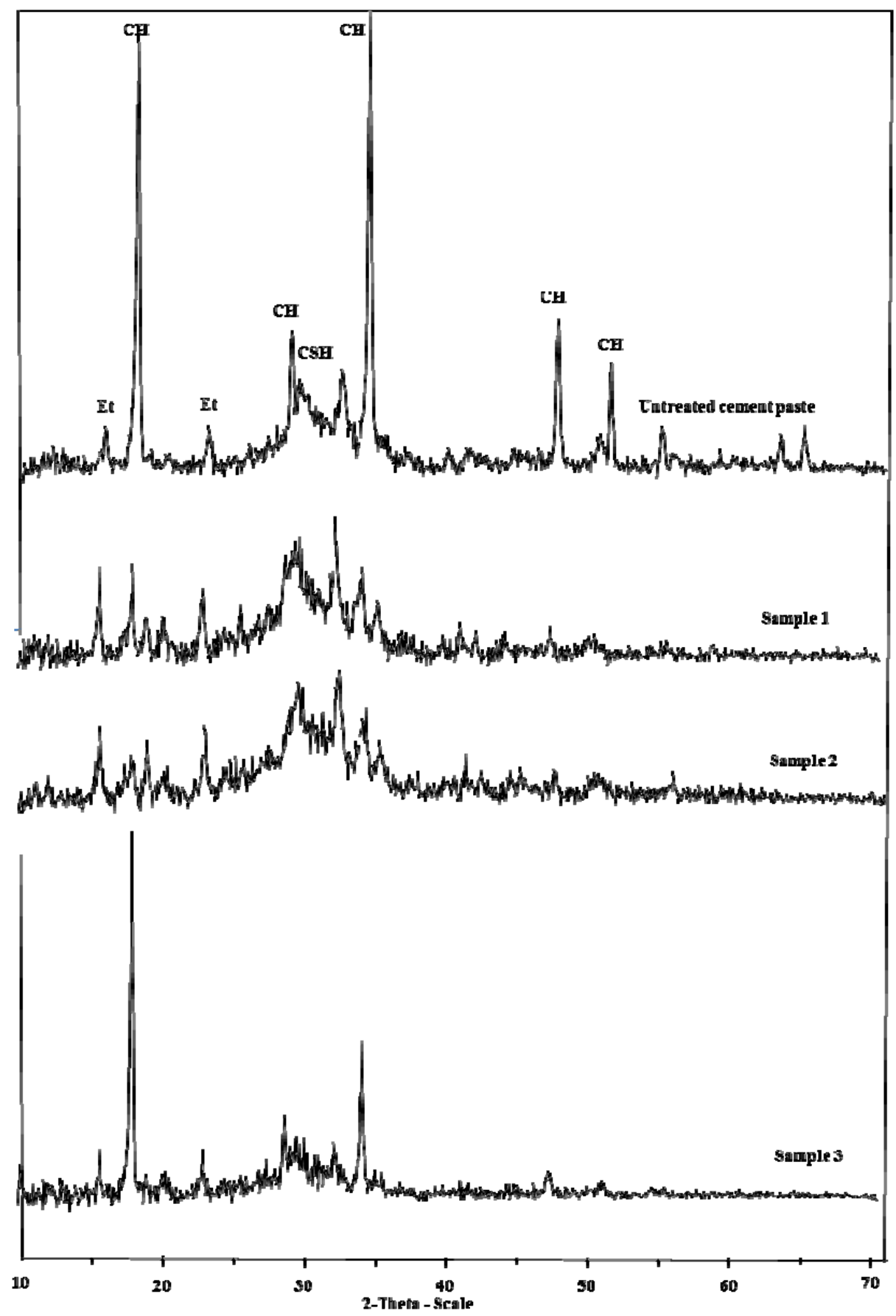

Figure 6. XRD results. $\mathrm{CH}$ : Portlandite, Et : Ettringite 


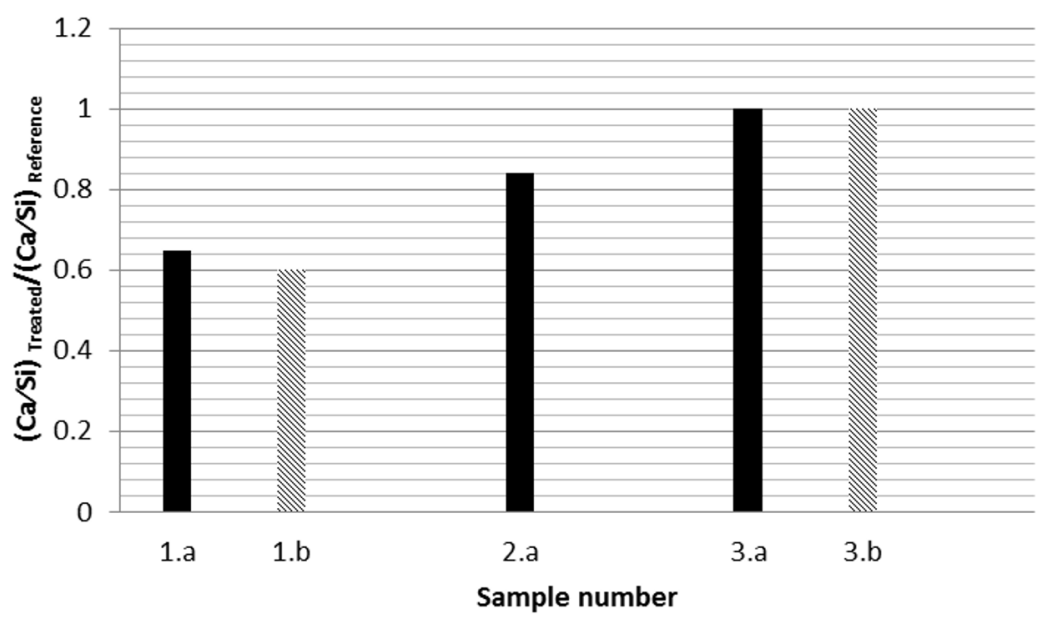

Figure 7. XRF analysis results

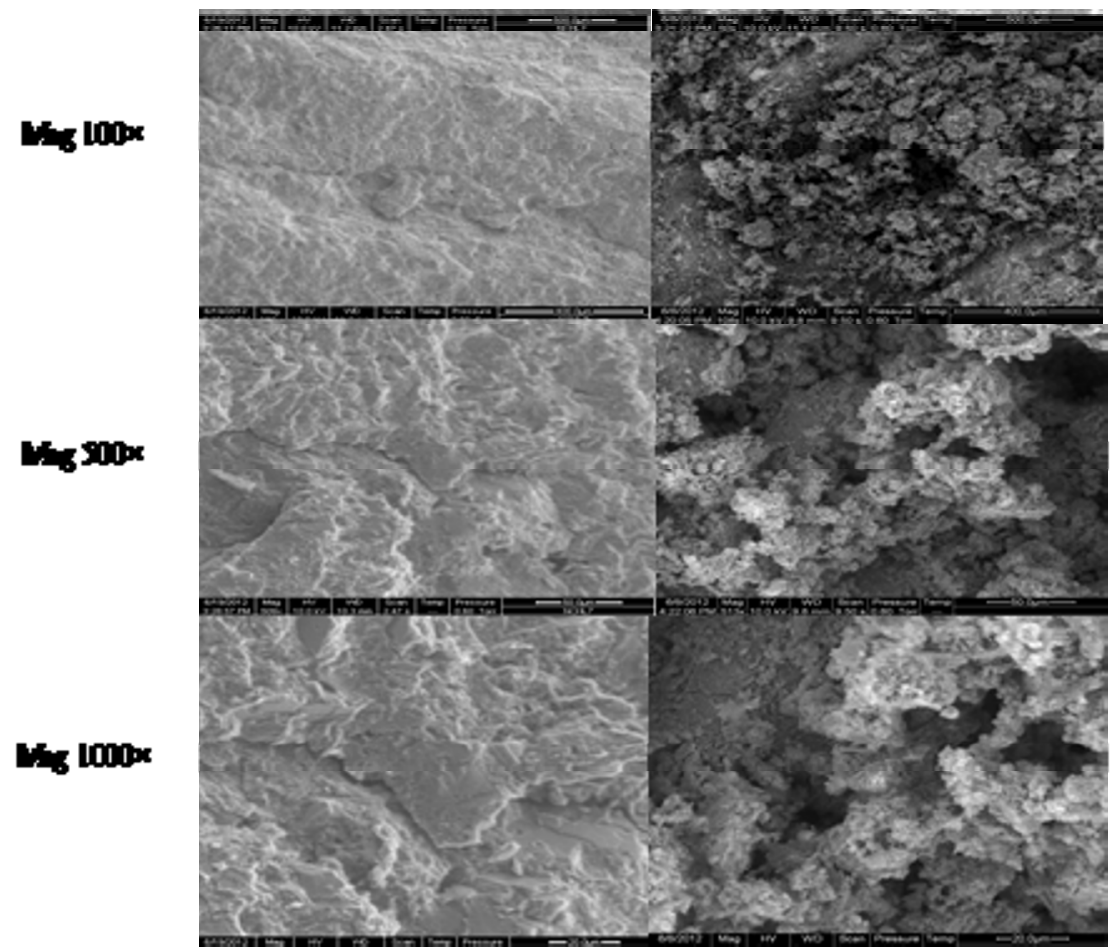

Figure 8. SEM analysis results 


\section{Concluding remarks}

An electrochemical migration method accelerating leaching of calcium from cementitious materials is presented. One of the direct applications of this method is manufacturing of samples for service life predictions of the concrete structures in nuclear waste repositories. Enabling a sample size of $\varnothing 50 \times 75 \mathrm{~mm}$ facilitates both mechanical tests as well as diffusion or permeability tests. In this method an electro chemical cell is designed in which a cementitious specimen is engaged as a part of the cell and in contact with an anolyte and a catholyte solution. When a sufficient electrical current and the correct chemicals are used this setup enables migration of calcium ions from the specimen's pore solution. The concluded setup parameters of the electrochemical cell require application of lithium hydroxide solution as anolyte and ammonium nitrate solution as the catholyte solution. The altered material is comparable with the leached material through natural immersion tests. It should be noted that although the results show that method ensue leaching of Portlandite without significant interactions with CSH phases, however more investigations regarding the mineralogical properties of the treated material is needed.

\section{References}

[1] F. Adenot and M. Buil, Cement and Concrete Research. 22 (1992) 489-496.

[2] P. Faucon, P. Le Bescop, F. Adenot, P. Bonville, J.F. Jacquinot, F. Pineau and B. Felix, Cement and Concrete Research. 26 (1996) 1707-1715.

[3] K. Haga, S. Sutou, M. Hironaga, S. Tanaka and S. Nagasaki, Cement and Concrete Research. 35 (2005) 1764-1775.

[4] H.S.a.S. Nakane, Materials Journal. 96 (1999) 208-212.

[5] H. Saito, S. Nakane, S. Ikari and A. Fujiwara, Nuclear Engineering and Design. 138 (1992) 151-155.

[6] H. Saito and A. Deguchi, Cement and Concrete Research. 30 (2000) 1815-1825.

[7] F.H. Wittmann, Materials Science Forum. 247 (1997) 107-126.

[8] C. Carde and R. François, Cement and Concrete Research. 27 (1997) 539-550.

[9] F.H. Heukamp, F.J. Ulm and J.T. Germaine, Cement and Concrete Research. 31 (2001) 767-774.

[10] E. Revertegat, C. Richet and P. Gégout, Cement and Concrete Research. 22 (1992) 259272.

[11] F.-J. Ulm, E. Lemarchand and F.H. Heukamp, Engineering Fracture Mechanics. 70 (2003) 871-889.

[12] L. Tang, Magazine of Concrete Research. 48 (1996) 173-179.

[13] Z. Abbas, E. Ahlberg and S. Nordholm, The Journal of Physical Chemistry B. 113 (2009) 5905-5916.

[14] J. Boman, Detector performance measurement techniques and computer software in an EDXRF-spectrometer applied to environmental and medical studies. $\mathrm{PhD}$ thesis (1990) 